\title{
Assessment of Pregnant Women's Knowledge and practice about Risks of Iodine intake Deficiency during Pregnancy
}

\section{Rania Saied Samuel 1; Entisar Mohamed Youness 2; Hoda Abd El Aziam Mohamed 3}

1. Bachelor of Nursing, Faculty of Nursing, Minia University

2. Professor of Obstetrics and Gynecological Nursing; Faculty of Nursing; Assuit University

3. Professor of Women Health and Obstetric Nursing, Faculty of Nursing, Mania University

\section{Abstract}

Background: Severe iodine deficiency during pregnancy is still a leading cause of maternal and fetal hypothyroidism, as well as preventable cognitive damage, all over the world. The aim of the study is to Assess of Pregnant Women's Knowledge and Practice about Risks of Iodine Intake Deficiency during Pregnancy. Research Design: A descriptive study design was utilized to attain the aim of this study. Subject and setting: Convenient sample (300) pregnant women who visited the general hospital in Mallawy district at Mania governorate in Egypt at the outpatient antenatal clinic over period (6) month. Tool of data collection: Structured interview questionnaire include (3 parts) (socio-demographic characteristics, pregnant women knowledge regarding iodine intake deficiency during pregnancy and pregnant women practice regarding iodine intake during pregnancy) Results: The study demonstrates (64.7\%)of the studied women have unsatisfactory knowledge about iodine intake during pregnancy.(68\%) of the studied women have unsatisfactory practice about iodine salt intake during pregnancy, with a high statically significance relationship between total level of knowledge and total practice about iodine salt intake during pregnancy. Conclusion: This study concluded that around two-thirds of pregnant women knowledge and practice towards iodine salt intake deficiency during pregnancy were unsatisfactory with highly statistically significant relationship between women knowledge and practice towards iodine salt intake deficiency during pregnancy. Recommendation: Educative programs to increase awareness on iodine are very important challenges for Egyptian pregnant women, in the coming years

Keywords: Pregnancy, Iodine Deficiency, Health Risks.

\section{Introduction}

Iodine deficiency disorder is a major public health problem around the world since it affects people of all ages, with nursing women and children being the most vulnerable. Iodine deficiency is expected to affect over two billion individuals worldwide, with about 50 million cases presenting with clinical symptoms. Iodine is required for the production of maternal and fetal thyroid hormones, which govern the fetal nervous system and brain development. In neonates, babies, and children, iodine deficiency produces maternal hypothyroidism, which can cause growth, cognitive, and psychomotor deficits (Lazarus, 2015).

Maternal malnutrition is linked to a higher risk of maternal morbidity and death, as well as a variety of negative pregnancy outcomes such as low birth weight and preterm birth, all of which may be linked to a higher risk of infant morbidity and mortality (Desyibelew \& Dadi, 2019). A 50 percent increase in iodine consumption is suggested during pregnancy for pregnant women to produce adequate thyroid hormones to meet both their own and their fetuses' needs. Because of an increase in maternal thyroxine (T4), production to maintain maternal euthyroid and transfer thyroid hormone to the fetus early in the first trimester before the fetal thyroid is functioning, iodine transfer to the fetus, particularly in later gestation; and an increase in renal iodine clearance, the iodine requirement during pregnancy is dramatically increased (Tuccilli et al., 2018).

According to a research conducted in Alexandria, approximately a third of pregnant women (28.8 percent) have insufficient iodine intake. Based on their dietary intake, iodine deficiency was common among pregnant women accessing health care institutions in Alexandria. As a result, it can be stated that this study cohort had a significant prevalence of iodine insufficiency (Ragab et al., 2019) as a result, the researcher wanted to assess of pregnant women's knowledge in this area as well as their practice concerning iodine deficiency.

According to (World Health Organization, 2019), It is advised that the nurse take an active role in ensuring that the mother and the fetus have a balanced diet during pregnancy. Nurses are in charge of giving nutrition education and counselling to pregnant women in order to improve their nutritional status. The nurses' main focus is on promoting a healthy diet by increasing the variety and amount of food consumed, ensuring adequate weight gain through sufficient and balanced protein and energy intake, and encouraging the use of micronutrient supplements, food supplements, or fortified foods on a consistent and ongoing basis.

\section{Aim of the study:}

- Assess of pregnant women knowledge and practice about risks of iodine intake deficiency during pregnancy.

\section{Research Question}

- What are the levels of pregnant women's knowledge and practice about the risks of iodine intake deficiency during pregnancy?

\section{Subject and Method}

Research design: To achieve the aim of the study, a descriptive study design was used. 
Setting: The General Hospital in Mallawy district at Mania governorate in Egypt was selected randomly to conduct this proposed study.

Subject: Convenient sample (300) of pregnant women who visited the general hospital in Mallawy district at Mania governorate in Egypt for receiving antenatal care at the outpatient antenatal clinic. Were selected according to the following criteria:

Pregnant women at any gestational age and don't have active thyroid disease.

\section{Tool of data collection:}

Structured interview questionnaire It designed by the researcher after reviewing relevant literature to collect data and contain three parts:

\section{Part one: (Socio-demographic characteristic).}

To collected data related to (age, education level, occupation, and, Residence) (obstetric history such as gravidity, gestational age, No of children) socio-demographic data assessment sheet was written in English and Arabic languages.

\section{Part two: (Knowledge assessment sheet).}

According to Charlton et al, (2010), the pregnant women's knowledge assessment sheet used to assess the knowledge of pregnant women about the importance of iodine (9) question such as (iodine deficiency information received? What is the thyroid gland? Hermon's of the thyroid gland? The function of the thyroid Hermon's? What is iodine? Importance of iodine? Recommended iodine requirement? the foods that had good sources of iodine? Known the thyroid gland test? Other questions assess women knowledge about the risk of iodine (4) such as, (what is iodine deficiency, what is the thyroid gland disorder. signs and symptoms of iodine deficiency? Consequences of iodine deficiency?

\section{Scoring system of knowledge level:}

The questionnaire included (13) questions. A Likert scale was used in a scoring system to evaluate the answers of the questionnaire that included zero score for the wrong answer, 1 for the incomplete correct answer, 2 for the complete correct answer. The total score ranged from zero grade $(0 \%)$ to 26 grades $(100 \%)$. The pregnant women were considered to have satisfactory knowledge when her total score is 13 grades $(50 \%)$ and above, and unsatisfactory knowledge if it is below 13 grades $(50 \%)$.

\section{Part three: (practice assessment sheet)}

According to Charlton et al, (2010), the pregnant women's practice assessment sheet used to assess the practice of pregnant women towards iodine salt intake during pregnancy include (6) question (eating or drinking food consumption of iodine as dark green leafy vegetables, fruits, eggs, milk, fish and yoghurt? taking dietary supplementation before pregnancy? Taking dietary supplementation during pregnancy? What type of salt do you mostly use at home? How often add iodized salt to your food at the table ? how often add iodized salt during cooking?

\section{Scoring system of practice level:}

The questionnaire included (6) questions. A Likert scale was used as a scoring system to evaluate the answers to the questionnaire that included (satisfactory) score for practicing the required action (50\% and above) and an unsatisfactory score for less than $50 \%$. The pregnant women were considered to have satisfactory practice when their total score is (3) satisfactory scores (above $50 \%$ ) and unsatisfactory practice if it is (2) and less unsatisfactory scores (less than $50 \%)$.

\section{The reliability and validity}

A jury of five specialists in the field of maternity nursing staff to evaluated the tool for content validity, and required changes were made. Cronbach's alpha test was used to determine the instrument's internal consistency.

\section{A pilot study:}

Following the development of the tools, a pilot research was conducted on ten percent of the sample (30) of pregnant women to assess the clarity, feasibility, and applicability of the tools, as well as the time required to apply them, and to make necessary changes to some of the questionnaire items. The pregnant women who took part in the pilot study were not included in the main study sample

\section{Procedure}

The Dean of the Faculty of Nursing at Mania University was asked to write an official letter to the head management of the general hospital in Mallawy, requesting authorization to collect data. Meeting with a selected location manager to discuss the study's aim, which enabled them to cooperate and facilitate a meeting with the pregnant women. The Researcher attending to selected hospital from 9.00 a.m. to 11.00 a.m. On two days (Saturday and Sunday) each week to collect data.

To collect data from pregnant women, the researcher held a meeting with each woman to introduce herself, explain the purpose and nature of the study, and how to fill out the questionnaire briefly through direct personal communication which took between 15 and 20 minutes, and obtain oral consent from the women before they were included in the study. The researcher told the women in the study were volunteers and that they right withdrawal's at any time.

The researcher presented an overview and clarification of the assessment tool question after getting the women's consent to participate in the current investigation. The pregnant women's were selected by the researcher based on inclusion and exclusion criteria., the doctor assisted the researcher in selecting the sample by performing a physical examination to confirm that the women don't have active thyroid disease. After that, the researcher asked her to fill the questionnaire and spent time with her while she completed the questionnaire.

The data collection period began in the middle of December 2019 and ended in the middle of March 2020 and completed from first September to November 2020.

Limitations: The COVID19 pandemic occurred during the data collecting process, which caused data collection to take longer because women were fearful of infection at the time and sought prenatal care at private clinics. and a lack of awareness about the risks of Iodine deficiency disorder ( IDD) during pregnancy. 


\section{Ethical Consideration:}

The Dean of the Faculty of Nursing and the research ethics committee of the Faculty of Nursing at Mania University gave their initial approval in writing. Pregnant women who took part in this study gave their oral informed permission. For the sake of anonymity and secrecy, each assessment sheet was coded, and the names of the pregnant women were not printed on the sheets.

\section{Statistical Design}

Data was collected, categorized, processed, tabulated, and computerized using the statistical package for social sciences program version (20) (SPSS). The percentage distribution, frequency, standard deviation, and mean, as well as the correlation coefficient, were employed as descriptive statistics. The data was evaluated with the relevant quantitative variable, and statistical significance was determined when the $P$ value was less than 0.05 . When the $P$ value was less than 0.001 , high statistical significance was regarded. When the $\mathrm{P}$ value was greater than 0.05 , no statistical significance was considered.

The Fisher exact test was used to determine the relationship between women's knowledge and the sociodemographic characteristics they selected as well as the related variables. (Ong \& Puteh 2017).

\section{Results}

Table (1) Distribution of Pregnant women regarding their socio-demographic characteristics $(\mathbf{N}=\mathbf{3 0 0})$.

\begin{tabular}{|c|c|c|}
\hline Socio demographic characteristics & $\begin{array}{l}\mathbf{N} \\
(\mathbf{3 0 0})\end{array}$ & $\%$ \\
\hline \multicolumn{3}{|l|}{ Age } \\
\hline$<25 \mathrm{yrs}$ & 99 & 33 \\
\hline - $\quad 25<30 \mathrm{yrs}$ & 128 & 42.7 \\
\hline - $30-35 y r s$ & 51 & 17 \\
\hline - $\quad>35 y r s$ & 22 & 7.3 \\
\hline Mean+SD /year $27.04+5.54$ & & \\
\hline \multicolumn{3}{|l|}{ Education } \\
\hline - $\quad$ Illiterate & 33 & 11 \\
\hline - $\quad$ Basic education & 56 & 18.6 \\
\hline - $\quad$ Secondary education & 130 & 43.4 \\
\hline - Highly education & 81 & 27 \\
\hline \multicolumn{3}{|l|}{ Occupation } \\
\hline$\bullet \quad$ Work & 67 & 22.3 \\
\hline - Housewife & 233 & 77.7 \\
\hline \multicolumn{3}{|l|}{ Residence } \\
\hline - $\quad$ Rural & 64 & 21.3 \\
\hline - Urban & 236 & 78.7 \\
\hline
\end{tabular}

Table (1): illustrates that $42.7 \%$ of the studied women aged ranged between 25 to $<30$ yrs with mean age $27.04+5.54$ years. Regarding education, $43.4 \%$ of them have secondary education, $77.7 \%$ of them are housewife, $78.7 \%$ of them lives in an urban areas.

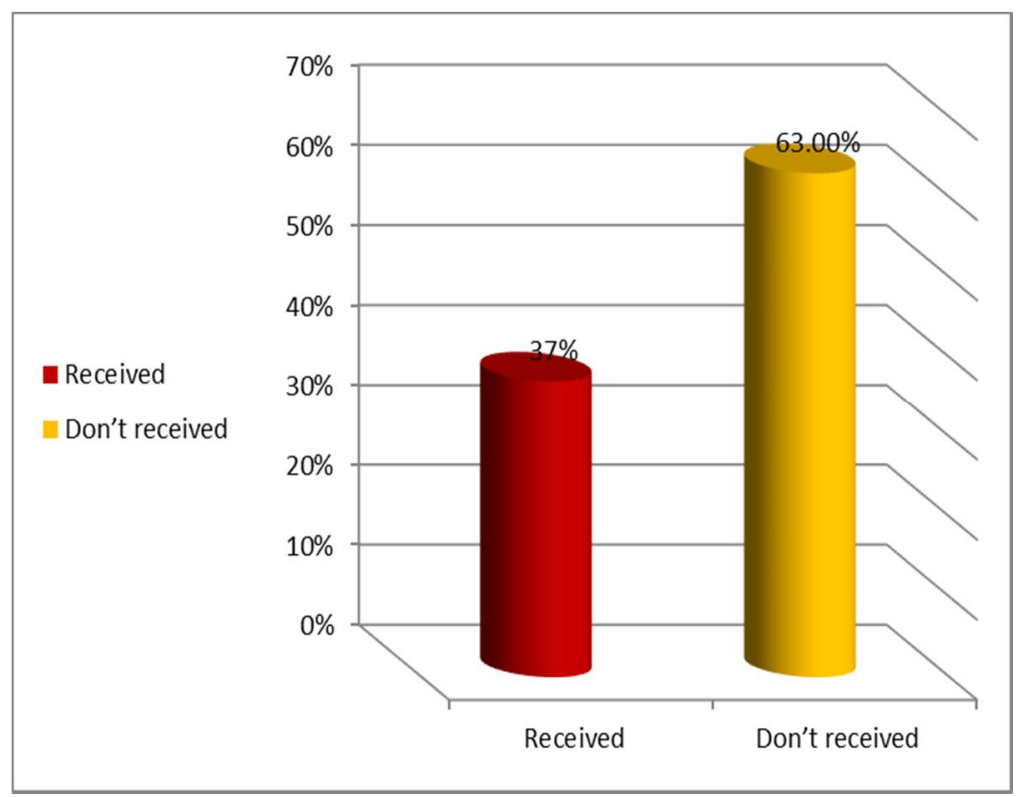

Figure (1) Distribution of pregnant women's regarding iodine deficiency information received $(\mathbf{N o}=\mathbf{3 0 0})$.

Figure (1): illustrates that $63 \%$ of the studied women don't receive information about iodine deficiency. 


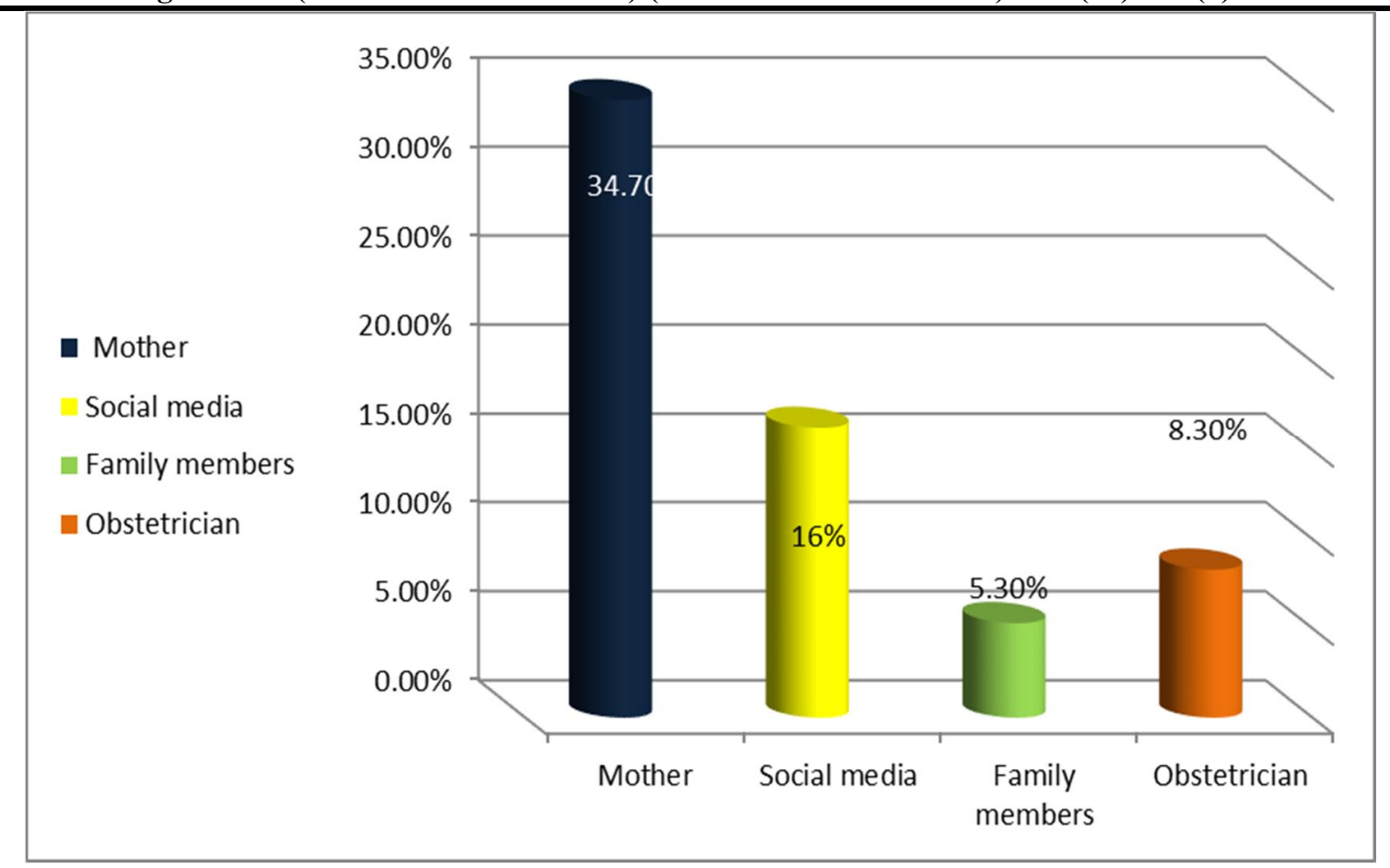

Figure (2): Distribution of pregnant women's regarding their source of information about iodine intake deficiency $(\mathrm{No}=300)$.

Figure (2): demonstrates that $34.7 \%$ of the studied women their source of knowledge mothers, followed by $16 \%$ of them from social media, $8.3 \%$ of them from their physician, finally $5.3 \%$ of them from family members.

Table (2) Distribution of pregnant women's knowledge regarding the food that had good source of iodine (No=300).

\begin{tabular}{|c|c|c|}
\hline Source of iodine $\left(^{*}\right)$ & No & $\%$ \\
\hline - $\quad$ Fruits & 28 & 9.3 \\
\hline - $\quad$ Vegetables & 28 & 9.3 \\
\hline • $\quad$ Eggs & 57 & 19 \\
\hline • $\quad$ Milk & 25 & 8.3 \\
\hline - $\quad$ Bread & 0 & 0 \\
\hline - $\quad$ Fish & 86 & 28.7 \\
\hline - $\quad$ Meat & 58 & 19.3 \\
\hline - $\quad$ Ice cream & 0 & 0 \\
\hline • $\quad$ Yoghurt & 8 & 2.7 \\
\hline - $\quad$ Iodized table salt & 58 & 19.3 \\
\hline - $\quad$ All of above & 117 & 39 \\
\hline - $\quad$ I do not know & 81 & 27 \\
\hline
\end{tabular}

* More than one response.

Table (2): demonstrates that 39\% of the studied women answer all of above for the food do think are a good source of iodine, followed by $28.7 \%$ of them answer fish, $27 \%$ of them do not know and $19.3 \%$ of them answer iodized table salt.

Table (3) Distribution of pregnant women's knowledge regarding the consequences of iodine intake deficiency during pregnancy $(\mathrm{No}=\mathbf{3 0 0})$.

\begin{tabular}{|c|c|c|}
\hline Consequences of iodine deficiency during pregnancy $(*)$ & $\begin{array}{l}\text { No } \\
(\mathbf{3 0 0})\end{array}$ & $\%$ \\
\hline - $\quad$ Spontaneous abortion & 45 & 15 \\
\hline - $\quad$ A stillborn baby & 30 & 10 \\
\hline - $\quad$ delay the growth of the fetus inside the uterus & 16 & 5.3 \\
\hline - $\quad$ The death of the child after birth & 0 & 0 \\
\hline - $\quad$ The low weight of the child at birth & 18 & 6 \\
\hline - $\quad$ Behavioral and cognitive impairment & 0 & 0 \\
\hline - $\quad$ All of above & 27 & 9 \\
\hline - $\quad$ Don't know & 216 & 72 \\
\hline
\end{tabular}

* More than one response

Table (3): describes that $72 \%$ of the studied women do not know the consequences of iodine intake deficiency during pregnancy, $15 \%$ of them answer spontaneous abortion and $10 \%$ of them answer a stillborn baby. 
口Satisfactory

$\checkmark$ Unsatisfactory

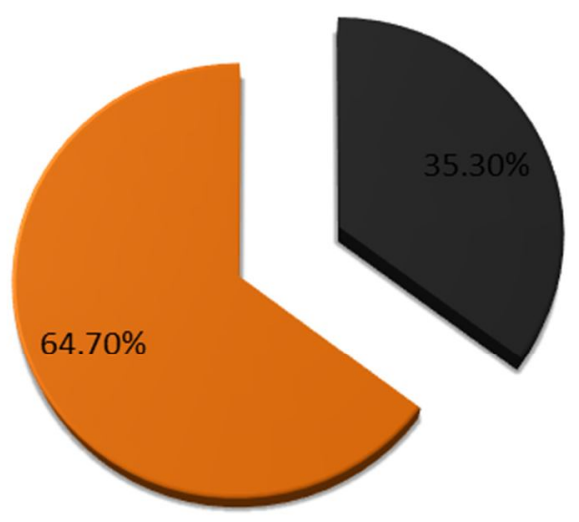

Figure (3): Distribution of pregnant women's total knowledge regarding iodine intake deficiency during pregnancy $(\mathrm{N}=300)$.

Figure (3): demonstrates that $64.7 \%$ of t. he studied women have unsatisfactory knowledge about iodine intake deficiency during pregnancy.

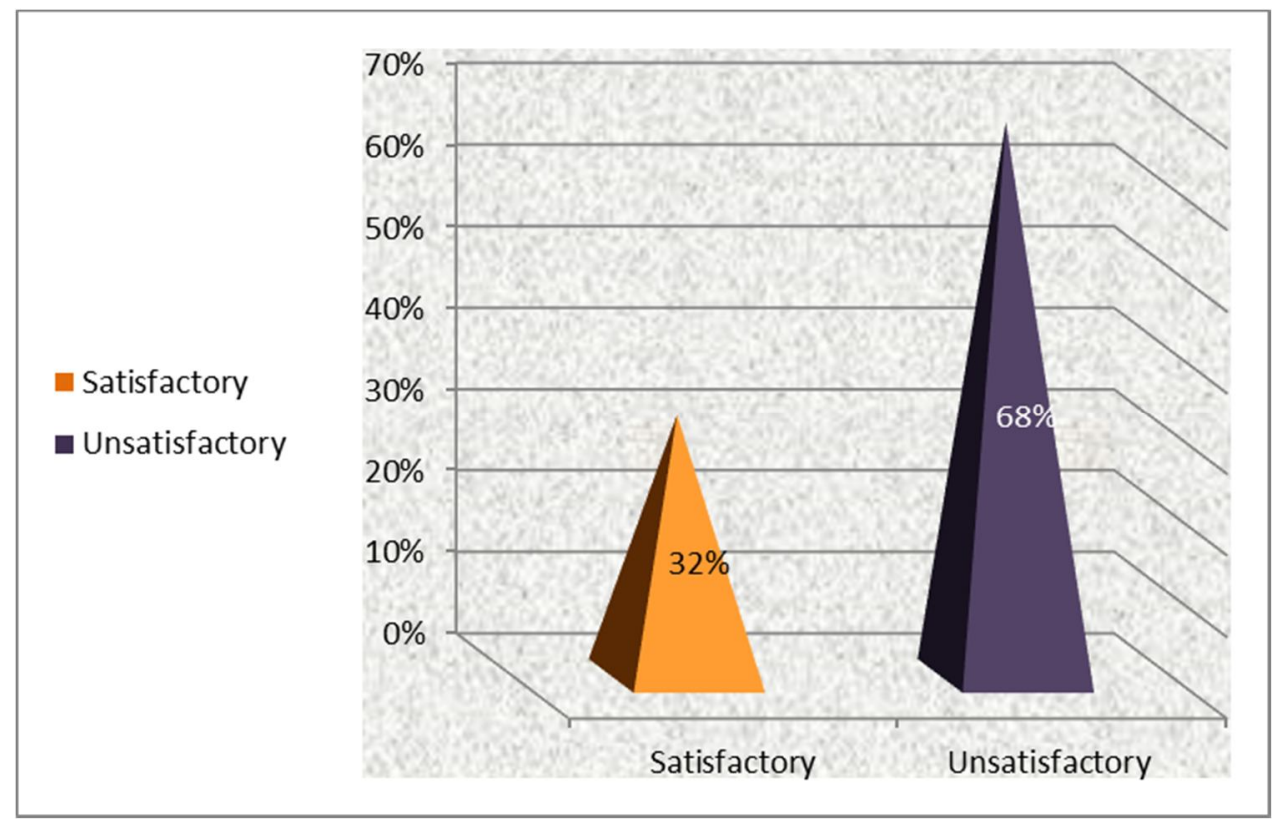

Figure (4): Distribution of pregnant women's regarding their total practice of iodine intake during the pregnancy $(\mathrm{N}=300)$.

Figure (4): demonstrates that $68 \%$ of the studied women have unsatisfactory practice about iodine intake deficiency during pregnancy.

Table (4) Relation between socio-demographic characteristics and pregnant women's total knowledge about iodine intake deficiency during pregnancy $(\mathrm{No}=300)$

\begin{tabular}{|c|c|c|c|c|c|c|}
\hline \multirow{2}{*}{\multicolumn{2}{|c|}{ Socio demographic characteristics }} & \multicolumn{2}{|c|}{$\begin{array}{c}\text { Unsatisfactory } \\
(\mathrm{N}=194)\end{array}$} & \multicolumn{2}{|c|}{$\begin{array}{c}\text { Satisfactory } \\
(\mathrm{N}=106)\end{array}$} & \multirow{2}{*}{$\begin{array}{l}\text { Fisher exact } \\
\text { ( p value) }\end{array}$} \\
\hline & & No & $\%$ & No. & $\%$ & \\
\hline \multicolumn{7}{|l|}{ Age } \\
\hline - & $<25 \mathrm{yrs}$ & 74 & 24.7 & 25 & 8.3 & \multirow{4}{*}{$\begin{array}{l}13.8 \\
(.003 * *)\end{array}$} \\
\hline & $25<30 \mathrm{yrs}$ & 77 & 25.7 & 51 & 17 & \\
\hline & $30-35 \mathrm{yrs}$ & 25 & 8.3 & 26 & 8.7 & \\
\hline$\bullet$ & $>35 \mathrm{yrs}$ & 18 & 6 & 4 & 1.3 & \\
\hline \multicolumn{7}{|c|}{ Educational level } \\
\hline
\end{tabular}


Minia Scientific Nursing Journal (Print - ISSN 2537-012X) (Online - ISSN 2785-9797) Vol. (10) No. (1) December 2021

\begin{tabular}{|c|c|c|c|c|c|c|}
\hline \multirow{2}{*}{\multicolumn{2}{|c|}{ Socio demographic characteristics }} & \multicolumn{2}{|c|}{$\begin{array}{c}\text { Unsatisfactory } \\
(\mathrm{N}=194)\end{array}$} & \multicolumn{2}{|c|}{$\begin{array}{c}\begin{array}{c}\text { Satisfactory } \\
(\mathrm{N}=106)\end{array}\end{array}$} & \multirow{2}{*}{$\begin{array}{l}\text { Fisher exact } \\
\text { ( p value) }\end{array}$} \\
\hline & & No & $\%$ & No. & $\%$ & \\
\hline . & Illiterate & 33 & 11 & 0 & 0 & \multirow{4}{*}{$\begin{array}{l}211.6 \\
\left(.000^{* *}\right)\end{array}$} \\
\hline & Basic education & 56 & 18.7 & 0 & 0 & \\
\hline & Secondary education & 105 & 35 & 25 & 8.3 & \\
\hline & Highly education & 0 & 0 & 81 & 27 & \\
\hline \multicolumn{7}{|l|}{ Occupation } \\
\hline & Work & 9 & 3 & 58 & 19.3 & \multirow{2}{*}{$\begin{array}{l}99.1 \\
\left(.000^{* *}\right)\end{array}$} \\
\hline s & House wife & 185 & 61.7 & 48 & 16 & \\
\hline \multicolumn{7}{|l|}{ Residence } \\
\hline & Rural & 29 & 9.7 & 35 & 11.7 & \multirow{2}{*}{$\begin{array}{l}13.3 \\
\left(.000^{* *}\right)\end{array}$} \\
\hline 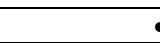 & Urban & 165 & 55 & 71 & 23.7 & \\
\hline
\end{tabular}

$* *$ : Highly significant difference $(\mathrm{p}$-value $\leq 0.001)$

Table (4): demonstrates that there was a highly statistically significant relationship between total knowledge of the pregnant women's and their demographic characteristics as age, educational level, occupation, residence at $(\mathrm{P}=<0.01)$.

Table (5) Relation between socio-demographic characteristics and pregnant women's total practice about iodine intake during pregnancy $($ no $=\mathbf{3 0 0})$

\begin{tabular}{|c|c|c|c|c|c|c|}
\hline \multirow{2}{*}{\multicolumn{2}{|c|}{ Socio demographic characteristics }} & \multicolumn{2}{|c|}{$\begin{array}{c}\text { Unsatisfactory } \\
(\mathrm{No}=204)\end{array}$} & \multicolumn{2}{|c|}{ Satisfactory $(\mathrm{No}=96)$} & \multirow{2}{*}{$\begin{array}{c}\text { Fisher exact } \\
\text { ( p value) }\end{array}$} \\
\hline & & No & $\%$ & No. & $\%$ & \\
\hline \multicolumn{7}{|l|}{ Age } \\
\hline$\bullet$ & $<25 \mathrm{yrs}$ & 76 & 25.3 & 23 & 7.8 & \multirow{4}{*}{$\begin{array}{l}11.2 \\
\left(.010^{*}\right)\end{array}$} \\
\hline$\bullet$ & $25<30 \mathrm{yrs}$ & 79 & 26.3 & 49 & 16.3 & \\
\hline$\bullet$ & $30-35 y \mathrm{yrs}$ & 30 & 10 & 21 & 7 & \\
\hline$\bullet$ & $>35 \mathrm{yrs}$ & 19 & 6.3 & 3 & 1 & \\
\hline \multicolumn{7}{|c|}{ Educational level } \\
\hline$\bullet$ & Illiterate & 33 & 11 & 0 & 0 & \multirow{4}{*}{$\begin{array}{l}215.4 \\
\left(.000^{* *}\right)\end{array}$} \\
\hline$\bullet$ & Basic education & 56 & 18.7 & 0 & 0 & \\
\hline$\bullet$ & Secondary education & 112 & 37.3 & 18 & 6 & \\
\hline$\bullet$ & Highly education & 3 & 1 & 78 & 26 & \\
\hline \multicolumn{7}{|l|}{ Occupation } \\
\hline$\bullet$ & Work & 12 & 4 & 55 & 18.3 & \multirow{2}{*}{$\begin{array}{l}99.4 \\
\left(.000^{* *}\right)\end{array}$} \\
\hline$\bullet$ & House wife & 192 & 64 & 41 & 13.7 & \\
\hline \multicolumn{7}{|l|}{ Residence } \\
\hline$\bullet$ & Rural & 29 & 9.7 & 35 & 11.7 & \multirow{2}{*}{$\begin{array}{l}19.2 \\
(.000 * *)\end{array}$} \\
\hline$\bullet$ & Urban & 175 & 58.3 & 61 & 20.3 & \\
\hline
\end{tabular}

- $\quad$ *: Significant difference $(\mathrm{p}$ value $\leq 0.05)$

- $\quad * *$ : Highly significant difference $(\mathrm{p}$ value $\leq 0.001)$

Table (5): Mentions that there was a highly statistically significant relationship between the total practice of the pregnant women's and their demographic characteristics as educational level, occupation, residence and at $(\mathrm{P}=<0.01)$. Also, there was a statistically significant relation with their age at $(\mathrm{P}=<0.05)$.

Table (6) Correlation between women total knowledge and total practice about iodine intake during pregnancy

\begin{tabular}{|l|l|l|l|}
\hline Variable & $\mathbf{r}$ & Knowledge & Practice \\
\hline Knowledge & $\mathbf{P}$ & & $.817^{* *}$ \\
& $\mathbf{r}$ & $.817^{* *}$ & 1 \\
\hline Practice & $\mathbf{P}$ & .000 & 1 \\
\hline
\end{tabular}

- $\quad * *$ Correlation is significant at the 0.01 level (2-tailed).

- PCC: P - value based on Pearson correlation coefficient.

Table (6): shows that was highly statistical significance relation between total level of knowledge and total practice about iodine intake during pregnancy.

\section{Discussion}

Women's health and reproductive performance, as well as children's health, survival, and development, all benefit from adequate and high-quality maternal nutrition (Zerfu, \& Biadgilign, 2018). As a result, optimal dietary iodine consumption during pregnancy, lactation, and early childhood is critical for the fetuses/newborn's proper neurodevelopment and growth (Mohamed et al., 2020).
Regarding to socio demographic characteristics the current study revealed that more than two-fifth of the studied women aged ranged between 25 to $<30$ yrs with mean age $27.04+5.54$ years, and have secondary education, more than three-quarter of them are housewife, and lives in an urban area. regarding obstetric data, more than one-third of the studied women have more than 28 weeks of gestational age, and around two-thirds of them their multi gravida and onethird of studied women have nothing child. 
A similar finding showed in a cross-sectional study conducted by Fereja et al.g( 2018) entitled "Prevalence of iodine deficiency and associated factors among pregnant women in Ada district, Oromia region, Ethiopia”. Who concluded that, the median age of the 356 women who took part in the study was 27 years. At the time of recruitment, women were in their first trimester $(9.0 \%)$, second trimester $(26.4 \%)$, and third trimester (64.6 percent ). Of the women $(45.0 \%)$ were illiterate, and virtually all $(95.2 \%)$ did not work outside the home.

On the other hand, incongruent sample sociodemographic characteristics studied by Azzeh and Refaat. (2020) on 1222 pregnant women, in Saudi Arabia, aimed to measure urine iodine concentrations (UIC) alongside the potential socioeconomic factors contributing towards iodine inadequacy in reproductive age and pregnant Saudi women from the Western province of KSA. The average age was 28.7 5.7 years in this case. Multigravidas $78.2 \%$, having more than four family members 64.3 percent, holding a university diploma $56.8 \%$, unemployed $78.2 \%$ According to the subanalysis, $29.8 \%, 28.8 \%$, and 41.4 percent of women were in their first, second, and third trimesters, respectively.

Regarding iodine deficiency information received, the current study illustrates that less than two-thirds of the studied women do not receive information about iodine intake deficiency. The researcher returns this finding to the shortage level of awareness about intake of iodine during pregnancy. Moreover, may return to the level of antenatal care.

This study finding goes in the same line with O'Kane et al. (2016) in their study entitled "Iodine knowledge is positively associated with dietary iodine intake among women of childbearing age in the UK and Ireland" carried on a total of 520 females of childbearing age, reported that only $9 \%$ of the studied women received information about iodine deficiency previously and had a significantly greater awareness of iodine, iodine deficiency and better knowledge of the dietary sources of iodine and the health problems associated with its deficiency than those who had never received information related to I (all $\mathrm{P}<0 \cdot 05)$.

Regarding the source of iodine deficiency information, the present study determined that more than onethird of the studied women their source of knowledge from their mothers, followed by less than one-fifth of them from social media, the minority of them from their physician and family members. May be due to the difference of culture between the studied communities and the difference in the educational level.

On the other hand, this result was unconjugated with Tegegne. (2019) in a study entitled "Assessment of Knowledge and Practice of Iodized Salt Utilization and Associated Factors Among Pregnant Women in Debreberhan Town" which revealed that $66.8 \%$ of the studied women receive information about iodine deficiency from media (TV, radio), $22.6 \%$ from friends, family, and neighbours, and $43 \%$ from printed material (newspaper, brusher, and leaflet)in addition to The current study findings are in harmony with Hine. (2016) in his study entitled "Assessment of iodine knowledge, beliefs and practices of pregnant women attending Western Australia's only tertiary women's and neonatal hospital" who revealed that more than half of the women received their dietary information from a doctor, followed by a midwife and the internets.

As regard to women identification of the food that had rich sources of iodine, the present study finds that slightly less than two-fifths of the studied women know all the foods that had a good source of iodine, and more than one-quarter of them answer fish, do not know and slightly less than one-fifth of them answer iodized table salt. From the researcher supposes that this finding is related to their antenatal education about rich sources of iodine.

This study finding agrees with the current study of AL Hadid et al .(2018) entitled "The Relationship between Iodine Nutrition, Thyroid Function and Obstetrical Outcomes for Jordanian Pregnant Women", clarified that only $27.6 \%$ of the participating women knew about the importance of fishcontaining diets as a source of iodine essential for the body mechanisms

This study finding disagrees with O'Kane et al. (2016), who reported that $39 \%$ of the women identified fish and seafood as the richest source of I and only $9 \%$ identified milk and dairy products. Younger women (18-25 years) had significantly better knowledge of the dietary sources of I than older participants $(41-45$ years $)(P<0 \cdot 001)$.

Other cross-sectional study findings by ÇíN and ÖZÇELIK. (2020) entitled "The Iodine Knowledge of Pregnant Women in an Endemic Goiter Area", carried on 150 pregnant women, in Turkey, revealed that Three main dietary sources of iodine in Turkey, fish, milk and dairy products and table salt are $68.0 \%, 20.0 \%$ and $77.3 \%$ of them correctly identified as good sources, respectively. ÇìN and ÖZÇELİK (2020) also reported that some of the pregnant women described meat $(27.3 \%)$, fruit $(22.0 \%)$ and bread $(34.0 \%)$ as the most important sources of iodine. About half of the pregnant could not correctly mark which sources of iodine are the best.

Related the women's knowledge about consequences of iodine intake deficiency during pregnancy, the current study proved that slightly less than three-quarters of the pregnant women answer do not know the consequences of iodine intake deficiency during pregnancy, less than one-fifth of them answer spontaneous abortion and the minority of them answer a stillborn baby. This current finding of the study may be interpreted due to the low level of education and lack of sources that provide information about iodine intake deficiency and its consequences and complications.

A parallel finding reported by Hine (2016), that over half of the study women (55.8\%) selected "I do not know" in relation to the list of health problems. While Approximately one-quarter of subjects selected the correct responses goiter and mental retardation.

Moreover, similar results claimed to be Al Hadid et al. (2018), that a few numbers of women $(10 \%)$ knew about the complications of iodine deficiency.

Contrary findings relate to health problems caused by iodine deficiency are presented explored by ÇíN and ÖZÇELIKK (2020), That $44.7 \%$ of pregnant women marked goiter, $63.3 \%$ mental retardation, $31.3 \%$ preterm birth; $29.3 \%$ knew that it can cause miscarriages and $26.7 \%$ of them stated that it can cause stillbirths. Moreover, the current study finding disagree Jin et al. (2020) in studyentitled"Use of Iodine Supplements by Breastfeeding Mothers Is Associated with Better Maternal and Infant Iodine Status" carried on 87 breastfeeding mothers, in New Zealand, reported that health issues associated with iodine deficiency correctly answered as the following: goiter $48 \%$, birth defects $38 \%$, mental retardation $26 \%$, impaired physical development during childhood $32 \%$. 
ÇIN and ÖZÇELIK (2020) also reported that the answers given by the women to the statements about the health problems caused by iodine deficiency are presented. The $44.7 \%$ of women marked goiter, $63.3 \%$ mental retardation, $31.3 \%$ preterm birth; $29.3 \%$ knew that it can cause miscarriages and $26.7 \%$ of them stated that it can cause stillbirth.

As regarding our current study demonstrates that slightly less than two-thirds of the studied women have unsatisfactory level of knowledge about iodine intake deficiency during pregnancy. From the researcher point of view, those prominent findings are related to low educational level, unavailable educational healthcare program.

This results in harmony with Abu-Baker et al. (2021) in a quasi-experimental study; entitled "The Effect of Health Education on Dietary Knowledge and Practices of Pregnant Women in Jordan", proved that after health education, the intervention group recorded significantly higher dietary knowledge score (mean $=19.30, \mathrm{SD}=0.88)$ compared to the control group score $($ mean $=14.36, \mathrm{SD}=2.11), \mathrm{p}<$ 0.001 .

On the other hand, contradictory finding proved by Almuzaini et al. (2019) in a study entitled "Assessment of knowledge and awareness regarding thyroid disorders among Saudi people", among 367 adult residents in Saudi Arabia, demonstrated that $57.32 \%$ of respondents had good knowledge, whereas $42.68 \%$ had poor knowledge of thyroid disorder diseases.

According to the current study demonstrates that more than two-thirds of the studied women have unsatisfactory practice about iodine salt intake deficiency during pregnancy. The researcher normalizes her study findings to the poor knowledge of the study women which directly reflect on their practice.

A supported view by Abu-Baker et al. (2021) illustrated that, the intervention group recorded a significant increase in practices score from the pretest (mean $=6.69, \mathrm{SD}=$ $1.97)$ to posttest $($ mean $=8.70, \mathrm{SD}=1.16), \mathrm{p}<0.001$. AbuBaker et al. (2018). Before health education, the result revealed no significant difference between the total dietary practices score of the intervention group (mean $=6.69, \mathrm{SD}=$ 1.97) compared to the control group score (mean $=7.02, \mathrm{SD}=$ 1.66), $(\mathrm{t}(193)=-1.24, \mathrm{p}=0.21)$. After health education, the intervention group recorded significantly higher total dietary practices score $($ mean $=8.70, \mathrm{SD}=1.16)$ compared to the control group score $($ mean $=7.02, \mathrm{SD}=1.66),(\mathrm{t}(193)=8.15, \mathrm{p}$ $<0.001)$. Furthermore, the result revealed a significant increase in the total dietary practices score of the intervention group from the pretest (mean $=6.69, \mathrm{SD}=1.97)$ to the posttest $(\mathrm{mean}=8.70, \mathrm{SD}=1.16),(\mathrm{t}(94)=-11.62, \mathrm{p}>0.001)$.

Remarkably, the current study demonstrates that there was a highly statistically significant relation between total knowledge of pregnant women's and their demographic characteristics related to age, educational level, occupation, residence at $(\mathrm{P}=<0.01)$. this finding due to difference of educational level and communities culture.

A supported view maintained by Tenaw et al. (2018) in a study entitled "Nutritional knowledge, attitude and practices among pregnant women who attend antenatal care at public hospitals of Addis Ababa, Ethiopia "that there was a positive significant association between the educational status of women $(\mathrm{AOR}=3.047,95 \% \mathrm{CI}(1.046$ to 8.873$)$ ), attitude $(\mathrm{AOR}=4.4,95 \% \mathrm{CI}$ (2.315 to 8.299)), number of pregnancies
$(\mathrm{AOR}=2.175,95 \% \mathrm{CI} \quad(1.034$ to 4.573$))$ and nutrition knowledge during pregnancy.

Moreover, Aktaç et al. (2018) in a study entitled Evaluation of nutrition knowledge of pregnant women before and after nutrition education according to sociodemographic characteristics. showed that pretest scores were found for factors, such as education level, work status, and the number of pregnancies; significant differences in both test scores were found for age and nutrition information $(p<.05)$. However, Post-test scores did not significantly differ according to the educational status, employment status, and number of pregnancies $(\mathrm{p}>.05)$

(Tegegne 2019) reported that, the women who had the household member greater than or equal to 6 were 6 more likely to have good knowledge than the participant who had the household member less than 6 . The pregnant women who had educational level from grade 9-12 were 9 times more likely to have good knowledge compared with the women who cannot read and write, and the women who can read and write were 5 times more likely to have good knowledge on iodine compared with the participant who cannot read and write.

Furtherly, the present study mentioned that, there was a highly statistically significant relationship between the total practice of pregnant women's and their demographic characteristics as educational level, occupation, residence, $(\mathrm{P}=$ $<0.01)$. Also, there was a statistically significant relation with their age at $(\mathrm{P}=<0.05)$ This result may be due to educational level, communities culture and level of knowledge reflect to total practice.

The current study supported with Tegegne (2019) reported that the women who had a primary school (1-8) were 2 times more likely to have good practice than those who cannot read and write and the women who had education level secondary (9-12) had 7 times more likely had good practices as compared to women who cannot read and write. Also, women with above secondary education level had 19 times more likely to have good practice compared with the women who cannot read and write.

Significantly, our study proved that are highly statistical significance between total level of knowledge and total practice about iodine salt intake during pregnancy. The researcher normalizes her study findings to the poor knowledge of the study women which directly reflect on their practice Which supported by Tegegne (2019) reported that the mother who had good knowledge on iodine and iodizes salt utilization had 6 times more likely had good practice on iodine utilization. Moreover. These results agree with Tenaw et al. (2018) and Hine (2016).

\section{Conclusion}

Based on the findings of the present study conclude that most women did not know the adverse health effect of low iodine in the diet and did not have adequate knowledge of good dietary sources with which daily requirement of iodine can be achieved. in addition, this study indicated that around two-thirds of pregnant women knowledge and practice towards iodine intake deficiency during pregnancy were unsatisfactory with highly statistically significant between women knowledge and practice towards iodine intake deficiency during pregnancy. 


\section{Recommendations}

Based on the results of the present study recommended that:

- There is a need to improve healthcare providers' knowledge of and adherence to the iodine supplement recommendation. Strategies within antenatal and postnatal services, as well as public health initiatives, are required to improve the knowledge and practices of healthcare providers which reflect on patient knowledge through health education.

\section{Further researches:}

- Effect of an educational program about iodine deficiency in pregnancy on pregnant women's knowledge, and practice.

\section{References}

(1) Abu-Baker, N. N., Abusbaitan, H. A., Al-Ashram, S. A., \& Alshraifeen, A. (2021). The Effect of Health Education on Dietary Knowledge and Practices of Pregnant Women in Jordan: A Quasi-Experimental Study. International Journal of Women's Health, 13, 433.

(2) Aktaç, S., Sabuncular, G., Kargin, D., \& Gunes, F. E. (2018). Evaluation of nutrition knowledge of pregnant women before and after nutrition education according to sociodemographic characteristics. Ecology of food and nutrition, 57(6), 441-455.

(3) Al Hadid, L. A., AlRajabi, O. Z., \& Al Barmawi, M. A. (2018). The Relationship between Iodine Nutrition, Thyroid Function and Obstetrical Outcomes for Jordanian Pregnant Women. Jordan Journal of Biological Sciences, 11(3).

(4) Almuzaini, A., Alshareef, B., Alghamdi, S., Munshy, A. A., Aljarallah, A. K. M., Salman, S. A. A., ... \& Alkhaldi, R. D. A. (2019). Assessment of knowledge and awareness regarding thyroid disorders among Saudi people. IJDMC, 3, 1070-1076.

(5) Azzeh, F., \& Refaat, B. (2020). Iodine adequacy in reproductive age and pregnant women living in the Western region of Saudi Arabia. BMC pregnancy and childbirth, 20(1), 1-12.

(6) ÇİN, N. N. A., \& ÖZÇELIK, A. Ö. (2020). The Iodine Knowledge of Pregnant Women in an Endemic Goiter Area: A Cross Sectional Study.

(7) Desyibelew, H. D., \& Dadi, A. F. (2019). Burden and determinants of malnutrition among pregnant women in Africa: A systematic review and meta-analysis. PloS one, 14(9), e0221712.

(8) Fereja, M., Gebremedhin, S., Gebreegziabher, T., Girma, M., \& Stoecker, B. J. (2018). Prevalence of iodine deficiency and associated factors among pregnant women in Ada district, Oromia region, Ethiopia: a cross-sectional study. BMC pregnancy and childbirth, 18(1), 1-8.

(9) Hine, T. (2016). Assessment of iodine knowledge, beliefs and practices of pregnant women attending Western Australia's only tertiary women's and neonatal hospital (Doctoral dissertation, Curtin University).
(10) Jin, Y., Luo, X., Ma, Z. F., Dong, Z., Carciofo, R., Li, X., $\&$ Skeaff, S. (2020). Adequate iodine intake among young adults in Jiangsu Province, China despite a medium iodine knowledge score. European Journal of Investigation in Health, Psychology and Education, 10(1), 554-563.

(11) Lazarus, J. H. (2015). The importance of iodine in public health. Environmental geochemistry and health, 37(4), $605-$ 618.

(12) Mohamed, MS., Nasr, MS., Elhalawany, SH., Tayeh, SS., Abbas, AM. (2020). Urinary iodine level assessment during the third trimester in a sample of Egyptian pregnant women and its relation to thyroid function. Int $\mathbf{J}$ Reprod Contracept Obstet Gynecol. 9:4350-5

(13) O'Kane, S. M., Pourshahidi, L. K., Farren, K. M., Mulhern, M. S., Strain, J. J., \& Yeates, A. J. (2016). Iodine knowledge is positively associated with dietary iodine intake among women of childbearing age in the UK and Ireland. British Journal of Nutrition, 116(10), 1728-1735.

(14) Ong, M. H. A., \& Puteh, F. (2017). Quantitative data analysis: Choosing between SPSS, PLS, and AMOS in social science research. International Interdisciplinary Journal of Scientific Research, 3(1), 14-25.

(15) Ragab, M. A., El-Mohsen, S. A., \& Tayel, D. I. (2019). Iodine Content in Commonly Consumed Egyptian Foods and Its Dietary Intake among Pregnant Women in Alexandria. INTERNATIONAL JOURNAL of ADVANCED SCIENTIFIC and TECHNICAL RESEARCH, 2(9). .26808/rs.st.i9v2.03"https://doi.org/HYPERLINK "https://doi.org/10.26808/rs.st.i9v2.03"10HYPERLINK "https://doi.org/10.26808/rs.st.i9v2.03".HYPERLINK "https://doi.org/10.26808/rs.st.i9v2.03"26808HYPERLINK "https://doi.org/10.26808/rs.st.i9v2.03"/rs.st.iHYPERLINK "https://doi.org/10.26808/rs.st.i9v2.03"9HYPERLINK "https://doi.org/10.26808/rs.st.i9v2.03"vHYPERLINK "https://doi.org/10.26808/rs.st.i9v2.03"2HYPERLINK "https://doi.org/10.26808/rs.st.i9v2.03".HYPERLINK "https://doi.org/10.26808/rs.st.i9v2.03"03 Retrieved March 6, 2021, from Thyroid Disease Manager website: https://www.thyroidmanager.org/chapter/the-iodinedeficiency-disorders/

(16) Tegegne, M. (2019). Assessment Of Knowledge And Practice Of Iodized Salt Utilization And Associated Factors Among Pregnant Women In Debre Berhan Town, Central Ethiopia (Doctoral dissertation).

(17) Tenaw, Z., Arega, M., \& Tachbele, E. (2018). Nutritional knowledge, attitude and practices among pregnant women who attend antenatal care at public hospitals of Addis Ababa, Ethiopia. International Journal of Nursing and Midwifery, 10(7), 81-89.

(18) Tuccilli, C., Baldini, E., Truppa, E., D'Auria, B., De Quattro, D., Cacciola, G., ... \& Ulisse, S. (2018). Iodine deficiency in pregnancy: Still a health issue for the women of Cassino city, Italy. Nutrition, 50, 60-65.

(19) World Health Organization. (2019). Global status report on alcohol and health 2018. World Health Organization.

(20) Zerfu, T. A., \& Biadgilign, S. (2018). Pregnant mothers have limited knowledge and poor dietary diversity practices, but the favourable attitude towards nutritional recommendations in rural Ethiopia: evidence from a community-based study. BMC Nutrition, 4(1), 1-9. 